\title{
NOTAS SOBRE O CONTEXTO DE TRABALHO DO GRUPO MODERNIDADE/COLONIALIDADE | UNIVERSIDADE, HORIZONTES UTÓPICOS E DESAFIOS TEÓRICOS ${ }^{1}$
}

Notes on the work context of the modernity/coloniality group / university, utopical horizons and theoretical challenges

FREITAS, Altiere Dias de ${ }^{2}$

Resumo: Nesse texto busca-se compreender o contexto de atividade do Grupo Modernidade/Colonialidade. O pensamento decolonial é descrito como uma "escola de atividade", com seus membros organizando-se segundo alguns conceitos e posturas políticas libertárias. Alega-se também que o ambiente universitário dos EUA aparece como espaço básico de articulação inicial das ideias do grupo, apesar de suas perspectivas se ancorarem em um espacialidade não-ontológica, a América Latina. Por fim, os três principais teóricos do grupo, Quijano, Dussel e Mignolo, são brevemente comparados, com o objetivo de destacar a radicalidade teórica desse último. A tese é que Mignolo já organiza sua obra segundo a influência de um "ironismo" teórico que lhe traz características e problemas específicos, cujo enfrentamento é importante para manutenção do Pensamento decolonial como uma alternativa teórica substantiva.

Palavras-chave: Pensamento decolonial. Contexto. Universidade. Quijano. Dussel. Mignolo.

Abstract: This text seeks to understand the context of activity of the Modernity / Coloniality Group. The decolonial thinking is described as a "school of activity," with its members organized according to some concepts and libertarian political attitudes. It is also argued that the US university environment was the basic space for the initial articulation of the group's ideas, although its perspectives are anchored in a nonontological spatiality, Latin America. Finally, the three main theorists of the group, Quijano, Dussel and Mignolo, are briefly compared, in order to highlight the theoretical radicality of the latter. The thesis is that Mignolo already organizes his work according to the influence of a theoretical "ironism" that brings him specific characteristics and problems, whose confrontation is important for the maintenance of the Decolonial Thought as a substantive theoretical alternative.

Keywords: Decolonial thinking. Context. University. Quijano. Dussel. Mignolo.

${ }^{1}$ Recebido em: 11 Abr. 2019. Aprovado em: 05 Mai. 2019.

2 Doutor em Sociologia pela Universidade Federal de Pernambuco; E-mail: altieredias@hotamai.com 


\section{Introdução}

Desde os anos 1990 o movimento Modernidade/Colonialidade vem promovendo uma renovação teórica com importantes implicações políticas. A revisão dos fundamentos do conhecimento, instituições e valores ocidentais, subsumida no termo "colonialidade", permitiu aos diversos membros do grupo desenvolverem estratégias de pesquisas e intervenções teóricas críticas orientadas por uma ética libertária. São iniciativas que partem das universidades e visam instaurar uma relação orgânica com os modos de resistência, visões de mundo e utopias dos povos e grupos sociais que sofreram ao longo da história um reatualizado processo de silenciamento que tem na globalização neoliberal sua face mais contemporânea.

Grande parte das energias do grupo se concentra na tarefa de mostrar como a visão sobre a modernidade e sobre o conhecimento que o eurocentrismo nos legou contribui para a perpetuação de processos de exploração e racialização de regiões e povos. Existiria sim, outras perspectivas de conhecimento e de vida, que sobreviveram nos escombros das sociedades vitimadas pelos colonialismos e que poderiam ser base de uma nova compreensão e de novas práticas. Há uma plataforma teórica projetada pelo pensamento decolonial que, ao aludir a memórias, língua e história específica, permite falar em uma suposta "desobediência epistêmica" em relação ao eurocentrismo.

Mas apesar do pensamento decolonial projetar um lócus de enunciação específico, a "América Latina", e produzir categorias com grande poder heurístico e político, parece ser interessante esboçar uma intepretação que mesmo aceitando as importantes contribuições do grupo, consiga ir além de suas alegações mais autoconscientes. Isso exige encetar uma "sociologia do conhecimento" que articule o corpus em questão a uma dinâmica social e histórica. 0 pressuposto aqui é que nenhuma teorização é evidente por si, pois teorias são mediadas pela experiência e pela prática ${ }^{3}$. Há sempre um "pano de

\footnotetext{
${ }^{3}$ James fala da "metafísica" como uma busca teleológica pela "palavra" que expressa e domina o princípio do universo. Mas tal princípio nada mais é do que uma ancoragem, um molde, colocado em marcha dentro da nossa corrente de experiências. É um "programa para mais trabalho", como uma indicação das maneiras pelas quais realidades existentes podem ser modificadas. Em sua perspectiva, "teorias se tornam instrumentos, não respostas para enigmas a partir das quais descansamos. Não são colchões nos quais nos
} 
fundo" (Dewey, 1998, p. 211), um tempo/espaço, cultura e língua de onde parte o sujeito do conhecimento e isso ajuda a modelar suas visões sobre os fatos, fazer observações e interpretar os dados e o conhecimento produzido.

É impossível entender as ambições e os limites do pensamento decolonial sem entender o contexto de trabalho coletivo do Grupo Modernidade/Colonialidade. Ao fundar um vocabulário que procura superar o pensamento moderno, seus membros propõem uma nova perspectiva sobre fenômenos globais e de longa duração temporal, além de ter como ideal político a libertação dos sujeitos subalternizados. Assim, descrevo, na primeira parte do artigo, algumas linhas de pensamento muito importantes para o surgimento e desenvolvimento do Grupo Modernidade/Colonialidade. Enfatizo seu caráter transdisciplinar, multinacional e não hierárquico de organização. Muito embora assumo que certos acadêmicos possuem uma posição de destaque no grupo, o que lhes garante uma "liderança teórica". Sublinho a importância de Anibal Quijano, Henrique Dussel e, o que mais interessa aqui, Walter Mignolo.

\section{A verve teorizante e crítica do Grupo Modernidade/Colonialidade}

0 projeto Modernidade/Colonialidade 4 é um movimento acadêmico criado por intelectuais que estudam sobre e a partir da América Latina. "Sobre” porque a história e os povos dessa "região" são analisados, em sua complexidade, em livros e artigos bastante criativos que exploram a cultura, a língua e o pensamento surgidos por essas bandas a partir da instauração do dilema colonial. Tal “entidade histórica” (O'Gorman,1995), a primeira da modernidade, é vista como presa de uma totalidade opressora. Essa estrutura age como o monstro mitológico hibris, deglutindo o que se opõe a sua ação, impedindo a manifestação criativa e a exteriorização objetificante de "outras" formas de existir cujas

esticamos, mas sim nos permitem caminhar e, ocasionalmente, reconstruir a natureza com o seu auxílio". (James, 1921, p. 53).

${ }^{4}$ A ideia aqui não é fazer uma análise das origens intelectuais do projeto. Existem ótimos artigos que tratam disso, tais como ESCOBAR (2003),) e BALLESTRIN (2013). Minha descrição geral busca se apropriar de algumas de suas características gerais e de marcos históricos do surgimento do projeto com vistas a uma interpretação não exaustiva e pragmática de algumas armadilhas surgidas das escolhas teóricas do grupo, especialmente das de Mignolo.

REALIS, v.8, n. 02, Jul-Dez. 2018 - ISSN 2179-7501 
origens remontam até antes do colonialismo. Em sua mutabilidade apresentou um formato "teológico" e, posteriormente, "egológico" que deixou em seu caminho um rastro de povos, vítimas de processos de aculturação que, com muita dificuldade, reproduziam seus imaginários e formas de vida 5 .

Já o "a partir" se refere ao fato de que "América Latina" acaba sendo projetada também como uma ancora, um ponto específico em uma totalidade, a partir do qual o pensamento é construído. É um lócus de enunciação ${ }^{6}$. Apoiados na inflexão pós-colonial, ou seja, na crítica ao caráter autorreferido e violento da perspectiva Europeia, e na defesa da possibilidade de se imaginar para além das categorias e autoimagem eurocêntrica, afirmam a tangibilidade desse espaço não-ontológico, discursivo e de resistência (Costa, 2006). Para tanto, há uma valoração positiva da história, da língua, do pensamento e da experiência individual ou coletiva ocorridas em uma parte do mundo que, como outras, desde o início do chamado "sistema-mundo" (Wallerstein, 2004)77, permaneceu em uma posição subalterna. Esse resgate e potencialização do que foi violentado ao longo dos séculos, tem como finalidade a liberação "epistêmica" e a construção de futuros distintos.

Nessa empresa, busca-se ir além do latinoamericanismo das disciplinas tradicionais, que se reproduziu (e se reproduz), em várias manifestações, negando a alteridade daqueles que foram submetidos ao escrutínio investigativo (Grosfoguel, 2012). Tal subcampo dos "estudos de área", assim como o "orientalismo", durante muito tempo foi a atualização de uma perspectiva chamada de "eurocêntrica". Segundo a ótica decolonial, esse ponto de vista se reproduzia nas mais diversas disciplinas preocupadas em tematizar o "outro" em contraposição a um "mesmo" europeu, tal como a história, a antropologia, a

\footnotetext{
${ }^{5}$ Ou nas palavras de Mignolo "Do Renascimento europeu ao iluminismo, da teologia e teo-política do conhecimento à egologia e à ego-política do conhecimento, a institucionalização e o controle de significados tornaram invisíveis as histórias e os conhecimentos dos não-europeus" (2011, p. 193).

${ }^{6}$ Foucault, com sua análise arqueologia, buscou desvelar a "vontade de verdade" ocidental e suas nuances. Em livros como "As palavras e as coisas" (2007) e "Arqueologia do saber" (2015), procura mapear a reafirmação de ordens epistemológicas, determinadas geograficamente e culturalmente, que legitimam uma evolução social específica, a ocidental. É nessa base, procurando superá-la, que Mignolo desenvolveu a ideia de "lócus de enunciação". Ver, por exemplo, Mignolo (2001, p. 172); (2007, p. 41) ou (Mignolo, 1995, p. 4).

70 conceito de "sistema-mundo" é um antecedente importante ao pensamento decolonial. Wallerstein concebeu os "sistemas-mundiais" como sistemas mais ou menos autônomos, limitados por fronteiras e com duração específica. A partir dessa categoria, elaborou a ideia de minissistemas, impérios e economias mundiais. Em sua análise, o sistema mundial moderno foi concebido como a economia capitalista nascente ao redor do importante século XVI (Wallerstein, 2004).
} 
ciência política, etc. ${ }^{8}$ Seria praticada por estudiosos que assumiam a ideia de que a América Latina era um campo fértil de objetos de conhecimento e não de saberes. 0 Grupo Modernidade/Colonialidade assume a ideia de que, sim, é possível praticar um saber e desvelar saberes que são tão ricos quanto o dito conhecimento universalista que vem da Europa. "Europa" aqui também considerada como lugar de fala, ou seja, espaço nãoontológico que pode e é assumido por pessoas que vivem em culturas periféricas. É contra o caráter difuso, inconsciente e consequente dessa ameaça que o pensamento decolonial se erige.

Em sua forma talvez mais radical, o tecido social é abordado como constituído por fenômenos semióticos complexos e difusos, estruturas discursivas que plasmam possibilidades existenciais. Pode-se dizer que tal perspectiva hipertrofia a realidade, considerada como articulada em torno de uma lógica microfísica de poder que, elaborada teoricamente pelo decolonialista, visa provocar uma consciência que facilite processos de liberalização epistêmica e social. Sua compreensão, contudo, é realizada prioritariamente através de obras culturais, como livros, cartas e mapas, e apenas episodicamente em sua encarnação prática diversa nos povos ou grupos sociais tomados como objeto da colonialidade e potenciadores de processos de decolonização (Mignolo, 2003). Na diagnose de Mignolo, tudo, desde um livro escrito sob um mote teórico tradicional, passando pelo lugar marginalizado da medicina tradicional em comparação com a medicina de origem europeia, até uma visão da natureza como depósito inesgotável de matérias primas, pode ser visto como uma manifestação dessa totalidade. Há uma atitude de "mestre da desconfiança"9 ou ironista, lançando um olhar inquiridor sobre vários aspectos da vida social.

\footnotetext{
8 Sobre isso, Castro-Gómez afirma que "as críticas terceiro-mundistas ao colonialismo, como narrativas formuladas teoricamente pela sociologia, a economia e as ciências políticas, não podiam escapar ao âmbito desde o qual essas disciplinas reproduziam a gramática hegemônica da modernidade nos países colonizados. Seguindo as teses de Jacques Derrida, Spivak afirma que nenhum discurso de diagnóstico social pode transcender as estruturas homogeneizantes do conhecimento moderno. 0 que significa que nenhuma teoria sociológica pode "representar" objetos que se encontrem por fora do conjunto de signos que configuram a institucionalidade do saber nas ciências sociais modernas" (Castro-Gómez; Mendieta, 1998, p. 172).

${ }^{9}$ A ideia de uma "escola da suspeita" refere-se a análise feita por Ricoueur (1973) do modo como as obras de Freud, Nietzsche e Marx instauraram uma crítica da ideia da consciência como transparente diante do mundo e de si mesma. Esses autores procuram interpretar os elementos simbólicos, através dos quais tal consciência se manifestava: Marx, com sua teoria da ideologia, Freud com seus fundamentos inconscientes
} 
Sob a influência da tradição crítica, embora afirmando se descolar de seu estilo de pensamento (Mignolo, 2010, p. 8), procura-se realizar uma teoria que vá além da mera constatação dos fatos. 0 objetivo de conhecer é sobredeterminado pela ideia de que existe uma realidade social que precisa ser transformada e cuja modificação a intervenção teórica do grupo é fundamental. Se é no nível semântico, cultural, que a dominação se cristaliza, o combate e um heroísmo também se realizam nesse nível. Embora se negue o fato de que o pensamento decolonial possa ser tomado como uma perspectiva privilegiada de "acesso ao real", ao afirmar sua relação orgânica com subalternos e ao processar tais relações em posições políticas estáveis na teoria, pelo menos em Mignolo, parece haver a assunção de uma autoridade (Franzé, 2013). Essa teoria busca desvelar a gênese de nossos dilemas e, no mesmo movimento, retirar os grilhões que impem o florescimento de alternativos padrões de relação com a natureza, de outros imaginários espaciais, de um padrão de convivalidade mais democrático, de uma "ecologia de saberes" (Santos, 2010) que abarque formas ocidentais e não ocidentais etc. A dialética negativa aqui não é suficiente, pois deve se completar com o chamado "movimento analético". Refere-se, entre outras coisas, à atitude ética de ouvir o outro e de se sacrificar por seus apelos (Dussel, 1977, p. 163).

Pode-se dizer que o pensamento decolonial atualiza um "olhar sobre o passado a partir do presente" e pensando o futuro (Mignolo, 1995 p. 5). 0 grupo procura se afastar de uma compreensão evolucionista, unilinear e dual de história, característica de um modo europeu de pensar um telos modernizante, surgido endogenamente no "velho continente" e que se espalhou mundo afora. O grupo investe em uma interpretação distinta, focando em como fenômenos que possuem laços causais complexos devem ser pensados dentro de uma dinâmica sistema-mundista, em que "impérios" disputam entre si o controle de "colônias". O que está em jogo é o questionamento do modo elogioso e autorreferido que intelectuais, desde pelo menos o renascimento, aludem a um "processo civilizatório" eurocêntrico encarnado em virtudes como "razão", "verdade", "liberdade" e "justiça”. Em uma reconstrução das condições de possibilidades dessa experiência, os

e Marx com uma genealogia da moral e da vontade de verdade. Mignolo, bebendo na ideia de colonialide de Quijano, também procura desenvover sua teoria de interpretação da formação da consciência em uma situação de "colonialidade de saber". 0 que aqui enquadro na ideia de uma "tradição ironista". 
autores mostram a existência de um darker side da modernidade, caracterizado pelo espólio injustificado dos recursos de povos não europeus, a violência epistêmica, a opressão e a injustiça. As histórias do ocidente são marcadas, assim, pela distribuição racial e geográfica de benefícios para poucos e horrores para muitos.

Em outro nível, o quadro de análise enaltece e integra, em narrativas genealógicas, histórias e experiências sociais que se agregaram à modernidade no início do século XVI e que sobreviveram, apesar de relações corrosivas com a perspectiva eurocêntrica da história e que podem fornecer a base para distintas sociabilidades. Nessa perspectiva existe uma utopia que se diferencia das imagens fechadas da cidade ideal, como a do marxismo. É uma utopia que fala sobre "vários mundos possíveis", portanto várias utopias de mundos possíveis, convivendo e se relacionando de uma forma dialógica e não autoritária. Muito embora a concatenação dessa interpretação histórica e a articulação dos sistemas teóricos tenderem a autolegitimação, em Mignolo, sua manifestação é colocada como não arrogante, evitando o tom peremptório da razão tradicional. Contra o universalismo provinciano europeu, busca-se um universalismo verdadeiramente universal (Wallerstein, 2007).

E apesar da grandiloquente habilidade desconstrutiva e imaginativa, há um necessário chamado à práxis, ancorada em uma postura ética libertária diante das injustiças cometidas contra o chamado "Outro" da Europa. O que sustenta o projeto é o desejo de que as teorizações inovadoras ultrapassem os muros acadêmicos e atinjam aqueles que desde a primeira modernidade são vítimas de processos de subalternização: primeiro, os povos autóctones; depois, os grupos originários da África e as populações mestiças que foram se conformando nas ex-colônias espanholas e portuguesas que, apesar dos formalismos liberais, não conseguiram se expressar ou ser contemplados em seu devido valor pelos novos regimes. Um dos dilemas fundamentais que o grupo enfrenta é justamente realizar esse "objetivo político" apesar de teorias e metodologias marcadas pelos cânones acadêmicos, racionalizações que possuem limites intrínsecos no que se refere a sua capacidade de penetrar na "sociedade civil global" e expressar as cosmovisões e idiossincrasias dos grupos com os quais o grupo busca dialogar. 


\section{A relação tensa com a academia}

Apesar da vinculação ética e epistêmica à América Latina, tomada como um espaço não-ontológico, há o enraizamento em um contexto inequívoco: o universo acadêmico dos EUA $^{10}$ parece ter fornecido o ground zero, a base geral, para a articulação do grupo. Foi o ambiente onde ocorreram os primeiros encontros pessoais e seminários que deram origem a publicações que apontavam as tendências e temáticas que facilitariam uma unidade a um conjunto heterogêneo de pesquisadores (Ballerstrin, 2013). Além, é claro, de os debates correntes e iniciativas surgidas nos departamentos das universidades norte-americanas, como o pensamento pós-estruturalista, o Grupo de Estudos Subalternos Sul-Asiáticos etc., terem contribuído na conformação teórica do grupo e no surgimento de sua configuração inicial como "Estudos subalternos Latino Americanos" (Castro-Gómez; Mendieta, 1998). Soa paradoxal a tentativa de falar a partir da América Latina, mas com os pés firmes em um espaço gringo de uma chamada potência imperial e muitas vezes lançando a voz no idioma de Whitman.

O fato de o sistema universitário americano, modelo para muito do que hoje temos no mundo, permitir a experimentação é um antecedente importante. Foi lá que foi inventado o sistema de pós-graduações no final do século XIX, a ideia de disciplinas opcionais e, mais recentemente, a cristalização de estudos sobre as mulheres e os chamados "programas étnicos" nos anos 1970 (Wallerstein, 1996). 0 clima intelectual surgido pelos debates do "multiculturalismo", dos estudos culturais e da "identity politics" e o questionamento geral das instituições, práticas e discursos, devido à influência do pósestruturalismo e pós-colonialismo, pelo menos já a partir da década de 1960, alia-se a esse clima institucional flexível criando um contexto favorável ao funcionamento do grupo (Castro-Gómez \& Mendieta, 1998). Em termos mais gerais, o modelo liberal ou neoliberal

\footnotetext{
${ }^{10}$ Castro-Gomes e Mendieta afirmam que é complexa a situação dos novos questionadores do colonialismo. Em um contexto global, os subalternos estariam vinculados de maneiras diversas a redes que os ligavam às metrópoles ou às periferias. Afirmam "o assunto se complica quando os acadêmicos que teorizam estes problemas começam a ser conscientes de que estão falando desde uma dupla posição hegemônica: por um lado, a hegemonia frente a seus locais de origem devido a sua condição de pessoas que vivem e trabalham em universidades elitistas do primeiro mundo; por outro, a hegemonia que lhes garante o saber e a letra frente a outros imigrantes, a maioria dos quais lutam diariamente para sobreviver nos setores de serviços" (1998, p. 11).
} 
democrático funciona como o terreno a partir do qual o pensamento decolonial reage. É possível dizer, portanto, que apesar de assumir a América Latina como âncora perspectivista, seus objetivos gerais, sua verve crítica e o poder de mobilização transnacional do Grupo Modernidade/Colonialidade, se desenrolam em uma relação tensa com esse espaço ontológico. Contudo, não há um enquadramento geográfico inexorável que prenda o grupo. Nem mesmo, uma instituição, tal como "Frankfurt", que funcione como o quartel general e etiquete a produção feita pelos “decolonialistas".

Embora seus membros partilharem certa base conceitual e objetivos políticos, o grupo pode ser enquadrado mais como uma "escola de atividade" do que uma "escola de pensamento" (Gilmore, 1988)11. Não há um "mestre", cuja obra e exemplo são seguidos por um cortejo de pupilos, mas sim um grupo de pesquisadores que, lidando com temáticas diversas, em obras mais individuais ou coletivas, atualizam o ideal de um "pensamento outro". Isso permite a coexistência de diferentes estratégias de pesquisa, com a abertura para inovações epistemológicas e a projeção de "objetos" de estudo, localizados tradicionalmente fora das formações disciplinares (MIGNOLO, 1993). É possível identificar, contudo, algum nível hierárquico informal. Algumas figuras centrais acabam ocupando uma relevância maior devido a seu papel institucional, como catalisadores dos interesses do grupo, e também devido ao impacto seminal de suas produções. Dentre os autores mais citados destacam-se Dussel, Quijano e Mignolo, apesar de esse último relativizar seu papel diretivo nos caminhos tomados pelo grupo e insistir em seu caráter aberto e engajado (Maldonado-Torres, 2007, p. 192). Além de um grupo amplo de pesquisadores dessa primeira geração, em outro nível está um número crescente de acadêmicos e militantes, alguns dos quais pertencentes a uma "segunda geração" de decolonialistas que, socializados no vocabulário do grupo, puderam lançar-se no front decolonial.

Outra característica marcante dessa intelligentsia é seu caráter "indisciplinado" (Walsh et al, 2002). Seus membros possuem diversas ancoragens acadêmicas,

\footnotetext{
${ }^{11} \mathrm{~A}$ esse respeito é interessante a reflexão de que "O grupo pode ser considerado como uma comunidade de argumentação que trabalha coletivamente em conceitos e estratégias (...) Em outras palavras, há uma dimensão explicitamente coletiva no trabalho conceitual que, embora esteja organizada ao redor de um conjunto de conceitos formativos, é aberto. Esse senso de coletividade é reforçado pelo sentimento do potencial radical do projeto" (MIGNOLO \& ESCOBAR, 2013, p. 45)
} 
destacando-se a literatura, a semiótica, a filosofia, a sociologia, a antropologia e a história. Mas é justamente o afastamento de uma organização disciplinar um dos móveis centrais de sua atuação. Tais campos de prática acadêmica são encarados com desconfiança, pois em seus pressupostos, teorização e tradições (Wallerstein, 2006) estariam vinculados a uma perspectiva de conhecimento que justificou e ajudou a modelar uma estrutura de poder muito desigual para quem se localiza nas margens de um sistema mundial. E muito embora as abordagens decoloniais dependam dos cânones acadêmicos europeus, buscase transcender essa herança, valendo-se dela na atualização de uma perspectiva libertária que visa desvelar o potencial epistemológico de povos cuja história e experiência foram apagadas. Há, com efeito, um leitmotiv central em sua prática, a "desobediência epistêmica" (Mignolo, 2010). Ideal que projeta uma organização institucional distinta, ou melhor, a imaginação impossível de novas formas institucionais.

Nesse contexto de pensamento heterodoxo, como não poderia ser diferente, a relação com a universidade, lugar que reúne, dá sentido e potencializa as disciplinas, é tensa. Apoiados em uma interpretação foucaultiana da formação violenta e excludente da "organização disciplinar" (Foucault, 2014, p. 28), a universidade é identificada como instituição que foi estruturada e que estrutura um pensamento racional, universalista e racializador, meio e motor do processo de conversão cultural pelo qual a América Latina foi objeto desde inícios da colonização (Wallerstein, 1996). Critica-se seu formato mais contemporâneo por uma relação promíscua com os valores do mercado e sua incapacidade de contemplar formas de conhecimento que existem e resistem afastadas do circuito acadêmico (Mignolo, 2009a). Na visão do grupo, esse conhecimento "endógeno" às periferias, os "monstros do conhecimento" (Foucault, 2014, p. 32) fora dos padrões estabelecidos de verdade, permitiria a colocação de problemas para cuja abordagem os métodos e teorias tradicionais não teriam serventia. Ao contrário, distorcem-nos e impedem os estudiosos de lidar com nossa experiência histórica, conformando uma espécie de espejismo (Quijano, 2014, p. 644). Seria preciso, portanto, um novo saber, gestado e impulsionado em uma universidade diferente, capaz de refletir um mundo plural, complexo e distinto em muitos sentidos do representado no espelho.

Wallerstein (2006), buscando analisar as dificuldades do novo clima intelectual, nascido a partir da segunda guerra mundial, mostrou como o impulso inovador centrado 
na criação de novas estruturas "pós-disciplinares", esbarrava no status quo institucional, que repelia ou muito lentamente absorveria a novidade. 0 campo acadêmico, como mostra Bourdieu, tende a restringir o acesso a seus recursos simbólicos e materiais, conservando a reprodução de seus atores segundo critérios tradicionais, ritualizados em suas práticas cotidianas e em seus habitus (Bourdieu, 2004). E isso se faz mais forte quando o pretendente em questão se coloca não apenas como criador de outro "paradigma" (Khun, 2006), algo que poderia ser pensado como imanente a uma constelação de saber, mas sim de uma perspectiva que quer desmantelar a ideia de conhecimentos privilegiados, instaurados a partir do silenciamento e exclusão de ricas "gnosiologias". É um paradigma outro o que propõe o grupo. Não é à toa que a área mais receptiva ao pensamento decolonial tenha sido os "estudos literários", mais aberta à exegese bibliográfica e cultural, às inovações teóricas e à interpretação textual da realidade, elementos centrais da abordagem decolonial (Díaz, 2014, p.552).

A criação de conceitos como "colonialidade", seu complemento "decolonialidade"12, junto com uma particular ética de libertação, projetou um corpus que busca estabelecer critérios novos para julgar a si mesmo e a outras formações discursivas. 0 movimento revisionista e crítico do pensamento decolonial em uma disciplina como a sociologia, por exemplo, é de tamanha "ameaça" teórica e institucional, que a reação veio quase na mesma moeda. Entre os contra-ataques, para além da reserva moral de sujeitos não informados, destacam-se a tentativa de tornar inócuo o pensamento decolonial, identificando como alvo de sua crítica uma sociologia obsoleta, ou na argumentação que, partindo de premissas criticadas pelo Grupo Modernidade/Colonialidade, aponta os paradoxos e estreiteza de sua teorização. Por estar nesse limbo, por seu caráter desestabilizador, o pensamento decolonial atualiza-se ora como território ignorado ora como espaço atacado

\footnotetext{
${ }^{12}$ Colonialismo é o resultado de ações imperiais que tem o capitalismo como princípio e base dos modos de organização. Diz sobre períodos históricos e regiões geográficas aonde as ações imperiais se realizaram. Colonialidade, por sua vez, é um fenômeno histórico mais complexo, existindo desde o início da colonização até a nossa época histórica. Refere-se a um "padrão de poder" que naturaliza hierarquias territoriais, raciais, culturais e epistêmicas. É uma "estrutura discursiva", um conjunto de princípios, ideias e crenças, que promovem uma visão de mundo "eurocêntrica". É o chamado "daker side" da modernidade. A decolonialidade é um projeto político, ético e epistemológico de buscar transcender a colonialidade. Procura-se ir além da descolonização que, apesar de conquistar a independência jurídica-política das nações latino americanas, não provocou a eclosão de novos imaginários.
} 
por todos que procuram etiquetar, segundo cânones e gêneros específicos, essas propostas teóricas e políticas inovadoras ${ }^{13}$.

Mas, vista de uma outra perspectiva, a própria radicalidade dessa “teoria bárbara" 14 nasceu no ambiente universitário, que forneceu grande parte dos recursos materiais, simbólicos e os valores com os quais o movimento é reproduzido. A trajetória do grupo é feita de encontros acadêmicos, de livros e artigos que gestam um debate que serve como uma frente de batalha dentro das linhas inimigas. É possível pensar também que a experiência conformada dentro do universo acadêmico permite a seus membros desenvolver uma perspectiva do mundo própria, azeitada pelos recursos abstratos e o caráter quase hermético e ascético da vida cotidiana praticados nesses "lugares de produção de conhecimento" 15 que surgiram para substituir a escolástica e o pensamento religioso. Apesar da abertura para fora, a confiança nos grandes esquemas teóricos parece refletir essa tendência incestuosa. Para desmantelar a razão petulante e preguiçosa, indicando as condições de possibilidade e os vícios de suas premissas, usam-se também teorizações de largo fôlego. Abusa-se de uma "hiperracionalização" que, como colocou Fanon, parece caracterizar a tentativa do "colonizado erudito" de dar conta de sua condição marginal e racializada na "casa do saber" mundial (Fanon, 2008, p. 110). Muito embora se evite a soberba do que é espelho e afirme-se a qualidade provisória das ferramentas teóricas: são pontes menos importantes do que a travessia ${ }^{16}$.

\footnotetext{
${ }^{13}$ Rorty afirma que um pensamento inovador, tal como o de Derrida, pode cair em uma espécie de limbo, um "não lugar" que não pertence a nenhum gênero tradicional, limite disciplinar ou cânone. 0 desconforto que provoca pode ser apaziguado ao enquadrá-lo nesses espaços mais restritos, dependendo dos interesses daqueles que redescrevem a teoria original $(1989$, p. 133).

${ }_{14}$ Mignolo (2003, p.157), refletindo sobre as semelhanças e dessemelhanças entre a teoria crítica da escola de Frankfurt e a teorização pós-ocidental/colonial, afirma que são uma "espécie de 'teorização bárbara': uma prática teórica daqueles que se opõem ao conceito racional e asséptico de teoria e conhecimento, teorizando a partir da situação na qual foram colocados, sejam judeus, muçulmanos ou ameríndios".

${ }^{15}$ Em seu clássico estudo, Mannheim (2013, p. 131) sugere que a atividade no universo abstrato permite que o intelectual transcenda o imediato, mas pode também ser fonte de intoxicação quando se perde no êxtase das ideias. Essa distância da vida cotidiana, facilitada pelo surgimento do espaço privado, da individualidade e (por que não?) da segurança da institucionalidade universitária, aliado ao caráter ocioso, pode também criar uma visão sublimada da existência, longe das tensões e dos desafios "práticos", uma espécie de alienação.

16 Talvez seja interessante pensar na ideia rortyana de teoria aqui. Para ele "teoria sugeriria lançar um amplo olhar sobre um território a partir de uma distância considerável (...). Os teóricos metafísicos se especializaram em se alienar de um dado topos e olhá-lo a partir dessa visão larga" (1989, p. 96). Isso era encarnado na tentativa de tocar algo real, essencial, por detrás das aparências. Portanto, no eixo teórico, localizavam-se em uma dimensão vertical. Já as teorias ironistas localizavam-se em um eixo horizontal: são uma série de tentativas de olhar para trás, observando essas experiências dimiurgas dos metafísicos. Ou
} 
É no campo mesmo da teorização que surge a ideia de um "pensamento impossível" que abre espaços e busca orientar o surgimento de novas práticas e instituições, num movimento que Santos chama de "emergência" (Santos, 2010, p. 118), inclusive de uma nova universidade, já apontada em algumas experiências exitosas. Dussel inicialmente se ancora no que chama de movimento analético, que, segundo sua perspectiva global, amplia a crítica dialética. Quijano procura se apoiar também em uma teorização totalizante, mas, diferente do tradicional pensamento evolucionista, estrutural e dual, característico do pensamento ocidental ${ }^{17}$. Já Mignolo, entre outras coisas, diz fazer uma "hermenêutica pluritópica" (Mignolo, 1995, p.11). Todas são estratégias críticas que projetam um amplo tecido abstrato sobre a realidade, diagnosticando e indicando os caminhos para fora do "labirinto" que foi instaurado quando da colonização. Existe a noção de uma permanente tarefa a ser realizada. Os autores, além de procurarem realizar a superação de padrões de pensamento tradicionais assumem uma "missão social": projetar novas condições de possibilidades que reflitam uma realidade nova. E é a partir da adesão a esse discurso que novas pedagogias, sociabilidades e instituições, tal como a universidade, podem surgir.

\section{Modos de escapar da Colonialidade}

No entanto, está claro que o que etiquetei aqui como "pensamento decolonial" é mais complexo do que a descrição esboçada. Existem diversos vínculos teóricos e epistemológicos e um mesmo autor, se observado de forma transversal, apresenta facetas distintas. Na década de 1960, quando a filosofia da libertação se colocou a seminal pergunta "é possível uma filosofia latino-americana?" (Dussel, 1977), o contexto era outro. E a resposta afirmativa, que é a própria filosofia da libertação, implicava uma

seja, o assunto da teoria ironista seria a teoria metafísica. Ou "entendê-la tão bem a ponto de se ver livre da metafísica" (...) A teoria ironista seria uma ponte ou uma escada que deveria ser abandonada assim que o movimento de travessia tivesse sido feito.

${ }^{17}$ No "Colonialidad del poder y classificacíon social" (2014, p. 285), Quijano procura substituir uma velha totalidade por uma nova que considera fora do racionalismo ocidental. Essa totalidade é composta de instâncias distintas (econômica, autoridade, subjetiva, sexual), que são articuladas estruturalmente a partir dos conflitos entre pessoas e grupos. 0 autor afirma que são elementos heterogêneos, descontínuos e incoerentes, distantes no tempo e no espaço que entram em articulação sob o domínio de alguns eixos determinados pelos grupos vencedores que dão a história e a sociedade uma determinada individualidade. 
radicalidade tal que Dussel chega a usar aquelas palavras grandes como "sacrifício", "risco de morte" para se referir aos heróis, militantes e intelectuais, que se debatiam e eram abatidos em Estados totalitários ou de grande tensão política, sempre em nome "dos que tinham fome" (Dussel, 1977, p. 102). À época, o movimento "analético" era complementar ao dialético e o ethos era o do conhecimento como base para a práxis revolucionária dos subalternos localizados nas nações latino-americanas, presas do quase conflito entre Estados Unidos e União Soviética18. Parecia haver a compreensão de um "intelectual universal" como emissário de um discurso que balançaria o status quo ao fornecer bases para tomada de decisões libertárias que valoravam mais a transformação do mundo do que o foco em "novas interpretações".

No pós-muro de Berlim o pai da filosofia da libertação viria a refletir uma transformação de perspectiva que marcou toda uma geração de intelectuais. Pôde falar em "transmodernidade" (dussel, 2016) como conceito que indicava o caráter vivo e orgânico de uma "cultura popular", de elementos "tradicionais", não mais negados em sua contemporaneidade. Seria um material animado que, anterior à colonização, foi tocado pela primeira modernidade e participou do trágico processo de conformação da segunda modernidade. Era preciso afirmar a força, a resistência e o potencial dessas modernidades alternativas que possuem cosmovisões, imaginários, valores e instituições que iluminavam a partir de outros tempos e espaços a formação do que se convencionou chamar de modernidade ou a pós-modernidade (Dussel; Fornazzari, 2002). Fala também de uma "ética material universal" já despida do caráter de urgência e da ameaça de

\footnotetext{
18 Dussel se preocupa em determinar o âmbito da filosofia da libertação ou "momento análético" e seu "método". Para tal, procura diferenciar-se de outras formas de conhecimento e prática: 1) Ciência, que se move no nível ôntico, e semanticamente lida com os entes naturais, fatos e dados. Busca uma explicação análitica-descritiva dos "porquês" das coisas. A atitude fundamental aqui é uma tentativa de "objetividade", de escapar de seu vínculo histórico social, de valores em nome da "cientificidade"; 2) 0 nível dialético, que se move no nível ontológico e semanticamente lida com as totalidades, buscando alcançar o fundamento do sistema. Busca a análise do sistema a partir do que dá fundamento ao horizonte do ser. Nega seu caráter inexorável a partir de valores que parecem se realizar no próprio sistema; 3) 0 nível analético, que tem como categoria fundamental a exterioridade, o além do horizonte do sistema, apoiado na concepção metafísica da liberdade humana. Refere-se à atitude ética de ouvir o outro e de se sacrificar por seus apelos. A dialética negativa não é suficiente, pois essa nega a negação a partir do próprio sistema. Insiste que esse nível não é científico, nem mesmo teórico pois depende mais de uma ética e de uma práxis. Ver o capítulo $\mathrm{V}$ (1977).
} 
danação que conformou a crítica da primeira "ética da libertação" 19. Enfim, com as transformações históricas e a emergência dos discursos historicistas e humanistas, a ênfase na crítica do discurso como objeto de poder, o campo de batalha passa a ser cada vez mais o campo do conhecimento. E embora não se possa anunciar verdades e esperar sacrifícios em nome de sua realização, busca-se novos horizontes utópicos que estimulem mudanças sociais.

Em um contexto de abertura "multicultural" e de questionamento da burocratização de países que conseguiram realizar o socialismo real, o marxismo, a base mais segura para a palavra legitimada, foi passado em revista. Um lugar comum na redescrição efetuada pelo pensamento decolonial é apontar o demasiado evolucionismo e eurocentrismo do próprio Marx como incapaz de compreender a realidade latino-americana, criada a partir de um colonialismo que pouco era levado em conta nas análises do materialismo histórico e dialético (Mignolo, 2010, p. 24). 0 descompasso entre herança intelectual e realidade local foi esboçado de forma paradigmática na obra de Mariátegui (1975). Lidando com a realidade peruana, o marxista latino americano transcendeu o modelo proletário e socialista como fundamento de uma revolução social. Elegeu o "indígena" como figura chave no processo de mudança social e o ayllu andino, comunidade indígena baseada na reciprocidade, como instituição fundamental para escapar do atraso em que o colonialismo havia colocado o seu país. O elemento "étnico", "racial", passou a ser importante na interpretação da realidade latino-americana.

Tal como Dussel, Quijano também parece refletir essa inflexão. Sua perspectiva da "dependência", expressa no "Dependência, Cambio social y urbanización em latinoamérica"20, já é em si bastante interessante, pois situa processos sociais e produtivos na América Latina, como a "urbanização", em uma ordem capitalista mundial como decorrentes da relação entre "periferia e centro". No entanto, como é comum nas teorias da dependência, o foco da análise é basicamente a relação entre estruturas

\footnotetext{
19 “Esta nova redação é distinta não só por ser escrita vinte anos depois, mas, principalmente, porque nestes anos mudou a situação histórica, amadureci uma nova perspectiva e desenvolveu-se um discurso transformado da ética na filosofia contemporânea" (DUSSEL, 2012, p. 14)

20 QUIJANO, Anibal. (2014). Dependencia, cambio social y urbanización en Latinoamérica. In: QUIJANO, Anibal. Cuestiones y horizontes. De la dependecia historic-estrutural a la colonialidade/decolonialidad del poder. Buenos Aires: CLACSO. p. 75-125.
} 
políticas e sociais atrasadas e a dependência econômica nacional ou regional. Concentrase mais na "infraestrutura" e no lugar ocupado pelos países e pessoas no modo de produção capitalista ou naquilo que Walllestein chama de "sistema-mundo". Contudo, em uma etapa posterior de seu pensamento, Quijano abandona esse tipo de abordagem totalizante centrada principalmente na economia. Mobiliza uma perspectiva multidimensional, agregando níveis que se querem descontínuos e incoerentes entre si e dentro de si, apesar da integração em uma universal "estrutura de poder". Com efeito, esboça, no "Colonialidad del poder y classificación social” 21 , um edifício teórico em que a "colonialidade de poder", fundamento da racialização dos povos e lugares, passa a ser o elemento explicativo central. E a resistência à subalternização passa não por Estados nacionais forte, burguesias conscientes ou processos revolucionários radicais, mas sim pela busca dos fundamentos identitários de novas instituições e pela resistência política, centrada na valoração de subjetividades, línguas e cultura de povos outros que não os europeus.

Inscrito na tradição peruana de Mariátegui, o interesse de Quijano pelo "comunitarismo" também suscitou um redirecionamento do quadro teórico com o qual buscava entender a realidade latino-americana, além de fornecer um paradigma para a criação de estratégias de libertação. Quijano crítica o que chamava de vitória da "burocratização" da vida e difusão da "razão instrumental", seja em sua versão hegemônica com a vitória do homo economicus, seja mais progressista com a desalentadora realidade de megapartidos, descolados do povo, e fundamentados em uma violência contra a vida. Questiona-se a respeito da viabilidade de uma gestão democrática, solidária e recíproca dos mecanismos de decisão e de produção em comunidades vivendo dentro e para além das institucionalidades vigentes em países da América Latina. Aponta, no artigo "Do 'polo marginal' à la 'economia alternativa'22, a novidade de um "comunitarismo" observado, surgido em no contexto neoliberal, muito diferente de sua versão tradicional, de origem indígena. Nessa busca por saídas para uma situação mundial de pauperização existencial e material dos que não experimentavam os benefícios do

21 Ibidem, p. 285-331.

22 Ibidem, p. 215-263. 
sistema econômico, Quijano questiona se diversas iniciativas locais não poderiam gerar práticas revolucionárias.

Ainda que articulada à dinâmica global do capitalismo, há um "sentido etnográfico" emergente em Quijano, especialmente quando se refere à CUAVES (Comunidade Urbana Autogestionária Villa El Salvador). Sua herança sociológica, terreno de uma antiga disputa entre "ação" e "estrutura", além de análises dos quadros mais amplos a partir dos quais os sujeitos agem, permite uma sensibilidade às dores e aos métodos cotidianos através dos quais os atores sociais constroem sua existência. Nesse momento, Quijano, ao invés de apontar fórmulas estabelecidas de saída, vai para o "terreno", recebendo a influência de formas locais e cotidianas de solidariedade e de imaginários econômicos e sociais que buscavam resistir às tendências hegemônicas. Testemunha também, no "El 'movimento indígena' y las cuestiones pendientes em América Latina"23, o processo que chama de cholificación no Peru, para cuja compreensão exige-se sensibilidade para lidar com uma dinâmica complexa que envolve a existência marginal de amplas populações "mestiças", de origem indígena, e a reconfiguração de seus valores e práticas em um ambiente em processo de urbanização. Em uma fase mais tardia, bem mais "decolonial”, tal como demonstrado no “'Bien vivir? Entre el 'desarrollo' y la Des/colonialidad del poder"24, sentindo a necessidade de fundamentar a luta em uma "metafísica não ocidental", se apropria da antiga noção de buen vivir ou sumak kawsay, conceito de origem quéchua, base para a utopia de uma sociedade futura igualitária e "sustentável”.

Esse rápido percurso sugere que, ao sabor das contingências históricas, e do surgimento de novas influências intelectuais, as perspectivas desses autores sofreram importantes transformações. De uma noção de teoria mais metafísica, ou seja, da linguagem como capaz de representar verdades ou expressar fundamentos transcendentais, sofreram influência das tendências pluralistas, culturalistas e desconstrutivas mais contemporâneas. Dussel fundamenta sua teoria da libertação, inicialmente, de uma forma quase transcendental, ao imaginar uma ideia de "Outro", oposto ao "Mesmo", quase como uma teologia secular, obviamente influenciada pela teologia da libertação. Muito embora, mais tarde, abre-se a uma visão pluralista e uma

23 Ibidem, p. 635-667.

24 Ibidem, p. 847-859. 
ética mais comunitarista, com a espiritualidade como um elemento central. Diferentemente de Dussel, vinculado à filosofia, Quijano parte do terreno da sociologia, mas também se abre a uma perspectiva menos preocupada com as oportunidades históricas e macroestruturas, e mais atenta ao terreno das possibilidades concretas, construídas comunitariamente. Tais autores, em um contexto de questionamento das grandes metanarrativas e expectativas históricas frustradas, parecem ter se tornado mais avisados sobre os limites das teorizações.

Mignolo, por sua vez, já realiza sua trajetória intelectual a partir do ceticismo em relação à metafísica ocidental e da luta por superá-la a partir das margens, estabelecendo critérios outros de validade do conhecimento. Na década de 1960, em sua formação básica, interessou-se por filosofia e pelo estudo das características dos textos dos cânones latino americano e moderno de literatura. Essa atenção fez Mignolo fixar habitação nos estudos literários e semióticos. Logo se voltou para problemas mais gerais da cultura latino-americana, com incursões na história do colonialismo (De Mojica, 1999). Sua ulterior concepção de "discurso colonial" promove, nos anos 1980, uma "mudança de paradigma" que foi de grande importância para a modelagem de uma perspectiva crítica em relação a fenômenos culturais e obras que surgiram no contexto das relações hierárquicas instauradas com a colonização (Díaz, 2014). Muito embora, Mignolo - em uma análise retrospectiva- reconheça os limites dessa abordagem propondo um outro conceito, o de "semiose colonial" que, segundo ele, escaparia da "tirania das noções alfabeto orientadas de texto e discurso" (Mignolo, 1993, p. 126).

Em seguida, em companhia de um conjunto heterogêneo de estudiosos, Mignolo concebeu um projeto teórico e ético audacioso: imaginar uma abordagem que abrangesse a constelação de experiências sociais e históricas dos "subalternos", no que veio a ser chamado "América Latina" (Group, 1993). Mas demonstrando uma atitude iconoclasta, marca de sua obra, apresentou desavenças teóricas não resolvidas que provocaram a dissolução do Grupo Latino-americano de Estudos Subalternos. Os motivos da desagregação parecem ter a ver com a opção, por parte de alguns membros, em reproduzir perspectivas, métodos e técnicas gestadas em outros lugares, em um processo de "importação teórica" que o autor argentino viria a atacar de forma frontal (CastroGomez; Mendieta, 1998, p.17). Refletindo sobre essa situação, ele aponta o fato de o grupo 
asiático produzir em inglês, "língua imperial", a partir de uma colonização anglo-saxã, oposta à colonização espanhola e ao uso do espanhol, língua sem força no mercado acadêmico e marginal no sistema moderno/colonial (Mignolo, 2003, p. 261). Daí Mignolo se propor a seguinte tarefa: fazer uma crítica ao discurso do "ocidentalismo" e dos estudos de área segundo uma perspectiva própria da América Latina.

Percebe-se que a complexa situação vivida por um tipo de teórico desconstrutor ${ }^{25}$ tem uma carga de dramaticidade ainda maior no contexto de atividade do pensador decolonial: além da "epistemologia da modernidade", ele teme ser domesticado por uma versão do conhecimento de outros "sujeitos colonizados", submetidos a uma dominação parecida, mas a partir de distintas "feridas coloniais". Diante desse quadro, Mignolo se colocou a tarefa de ir além do panorama intelectual existente, compreendendo a dinâmica de difusão das teorias, os limites e impedimentos que são erguidos diante de formas de conhecimento não ocidentais, além de fornecer alternativas viáveis para a emergência de um "pensamento outro"26. Nessa empresa, recorre ao auxílio de conceituações que problematizam tradicionais visões de "representação", "verdade" e "conhecimento". Mignolo assume uma "interpretação performática" da realidade que retrata a Filosofia e a Ciência como formações discursivas racializantes que emergiram no interior da afirmação imperial sobre o mundo (Mignolo, 2003). A crítica se realiza a nível epistêmico, desvelando os fundamentos, modos de dispersão e deslocamento da "colonialidade dos saberes".

Vem daí a suspeita desse autor em relação ao "racionalismo universalista". Como um bom "hermeneuta da desconfiança" (Hoyos, 2016, p. 607), coloca formas correntes de

\footnotetext{
${ }^{25}$ Refiro-me a interpretação de "desconstrução" de Rorty que, ao analisar Derrida, argumenta que este não cria um método, algo como um conjunto de regras e técnicas que devem ser aplicados segundo modelos estabelecidos, mas apenas uma "atitude": processos de revisão dialética, recontextualização, inversão de hierarquias. Algo muito presente na tradição filosófica exemplificada por Augustinho, Hegel e Nietzsche, entre outros (Rorty, 1989, p. 134). Mignolo parece concordar com essa visão, mas afirma que a perspectiva decolonial supera as limitações demonstradas pela desconstrução, que "apresenta em relação à experiência decolonial as mesmas limitações do marxismo em relação à "raça" (Mignolo, 2003, p. 438).

26 "Um pensamento outro, tal como concebo, é um pensar em línguas, que se dá através da tradução de diferentes códigos, bem como de sistemas e de constelações que circulam no mundo e abaixo do mundo. Cada sociedade ou conjunto de sociedades é uma ponte ou cruzamento de uma estruturação global. Qualquer projeto estratégico que não leve em conta e ativamente se engaje nesses movimentos está, talvez, condenada a ser devorado, voltar-se contra si mesmo, entropicamente". (KHATIBI, 1983, p. 61, apud MIGNOLO, 2003, p. 77).
} 
interpretação sob uma luz de dúvida, procurando flagrar, naquelas ideias, os modos sorrateiros pelos quais a colonialidade se reproduz (Álvarez Solís, 2010, p. 103). Isso resultou em um mapeamento global de uma dinâmica teórica que obedece à colonialidade de saberes, uma bússola que pode ser guia para aqueles que pretendem superá-la. Nessa tarefa, há também a ressonância da sempre pertinente questão da "Filosofia da libertação" (Dussel, 1977): é possível uma filosofia latino-americana? Mignolo retraduziu esse problema em sua ideia de que os subalternos coloniais não apenas têm uma cultura que pode ser estudada por disciplinas acadêmicas tradicionais e estudos de área, mas sim, possuem uma rica "gnosiologia" que, através de "pensadores limiares" (Mignolo, 2003), adquiriu a forma de uma "opção distinta" (Mignolo, 2011). 0 aparecimento do Grupo Modernidade/Colonialidade em 1998, unindo acadêmicos de múltiplas origens disciplinares, traduziu em uma dimensão "institucional" essa atitude crítica.

As teses de Mignolo visam, entre outras coisas, provocar uma reorganização das bases a partir das quais pensadores, acadêmicos e militantes dialogam com grupos submetidos à colonialidade. 0 autor argentino, ao longo de seus trabalhos, atribui um papel central a um novo tipo de "intelectual", capaz de se apropriar da herança intelectual do ocidente em benefício dos grupos, movimentos dos quais ele faz parte. Essa imagem "normativa" incluí a ideia de uma teoria/prática forjada na e a partir das memórias, história e da ferida provocada pela colonialidade. Mas sua prática não é só "negativa". Embora deva necessariamente passar pelo desvelamento dos mecanismos de poder que oprimem e silenciam suas comunidades de origem ameríndia, indígena, mestiça, etc., esses mesmos registros guardam uma potência epistêmica que aquele distinto intelectual deve se acercar para provocar novas utopias e possibilidades existenciais. Essa prática chamada, entre outros termos, de "pensamento limiar"27, "fronteiriço" e "gnosiologia" (Mignolo, 2003, p. 35), parece ser a marca que caracteriza o "intelectual decolonial".

\footnotetext{
${ }^{27}$ Mignolo diz que "o pensamento limiar é a epistemologia pluriversal (emergindo a partir de diversas experiências locais em momentos e espaços distintos, entre histórias locais ocidentais e histórias locais não ocidentais) que interconecta a pluralidade e a diversidade de projetos decoloniais" (MIGNOLO, $2012 \mathrm{p}$. XXII). Em outro lugar explica "um mundo com verdade entre parêntesis, aceito como universal, é um mundo guiado pela pluriversalidade como um princípio universal. Em um mundo pluriversal, fundado na verdade entre parêntesis, não há espaço para guerras. Isso significa que as diferenças entre trajetórias serão negociadas de uma maneira não imperial, o que significa que não haverá espaço para uma reocidentalização exclusiva" (Mignolo, 2011, p. 176).
} 
A questão é que, segundo Rorty (1989), todo "ironista teórico", ou seja, preocupado em concatenar um discurso que, para além do critério de originalidade e autorrealização de quem o mobiliza, se estabelece também a partir da ideia de uma utilidade social, recai em uma ilusão de relevância. A redescrição que realizam de outros autores, considerados superados por algum motivo, os fazem crer no caráter sublime do vocabulário que encontram como novidade. Além do mais, essa superioridade se realiza pela compreensão da importância que o discurso que exibem tem na provocação de novas possibilidades históricas, de processos de libertação, para "não intelectuais". Ou seja, no caso de Mignolo, por mais que sua teorização tenha absorvido as tendências historicizantes e construtivistas, especialmente a partir da abertura pós-colonial e do pensamento pósestruturalista, sua prática intelectual, gestada em um ambiente acadêmico, com seus ritos e capital específico ainda se realiza a partir de uma posição privilegiada. Até que ponto essa realidade é subsumida na prática realizada por Mignolo? Ou seja, até que ponto o "ironista decolonial" articula o ideal de redescrição e consciência da própria contingência com a prática posta em movimento em sua teorização? Como a sempre presente possibilidade de completa ignorância ou pouco valor que "homens comuns", envolvidos no esforço de reprodução de suas existências, possam atribuir a tais construtos abstratos são assumidos pelo intelectual decolonial?

\section{Considerações finais}

Nesse texto, procurou-se dialogar com o pensamento decolonial, apropriando-se de alguns de seus modos de experimentar a realidade. Representa, de fato, uma proposta concreta de resistência a uma colonização intelectual e oferece uma visão política inovadora em ligação orgânica com movimentos sociais e culturais que confrontam os modos mais contemporâneos através dos quais a colonialidade persiste. É inegável a ampliação de horizontes utópicos, críticos e teóricos, com consequências na vida cotidiana de amplas populações submetidas a uma hierarquia racial, que o Grupo Modernidade/Colonialidade promove. 
No entanto, é possível ir além das alegações mais autoconscientes sobre o valor acadêmico e político do grupo e retratá-lo "para além da teoria”. Isso significa, de um lado, esboçar uma "sociologia do conhecimento" em que as ideias sejam projetadas como existindo em determinado tempo-espaço (para além do tempo-espaço imaginado pelo pensamento decolonial). Vimos como a verve crítica e teorizante do Grupo Modernidade/Colonialidade teve grande impulso no contexto social e acadêmico americano, que forneceu grande parte de seus recursos teóricos e materiais, muito embora a teoria decolonial projete e defenda um outro espaço "não-ontológico", a América Latina.

É possível entender o pensamento decolonial segundo uma resposta acadêmica ao desafio colocado pela corrosão das grandes metanarrativas (Lyotard, 2009) tradicionais no pós-muro de Berlin. Sofrendo a influência dos novos movimentos sociais, novos contextos políticos e de "giros epistemológicos" (Martins, 2017), oferecem uma alternativa plausível às grandes expectativas iluministas e ao desespero niilista que engessou muitos intelectuais depois do "fim da história". Mas, paradoxalmente, isso muitas vezes ocorre segundo uma crítica semiótica centrada nos elementos discursivos que projeta uma macronarrativa que parece hipertrofiar a compreensão do social. 0 que pode resultar em uma "perda da experiência", ainda que por outras vias, muito diferentes daquelas apontadas por Boa Ventura de Souza Santos (2011).

Aqui entra outro nível de "contextualização" esboçado: cada autor possuí trajetórias específicas, o que resulta em perspectivas teóricas distintas. Apesar de em muitos momentos do texto o "pensamento decolonial" ser tratado como algo homogêneo, a comparação de alguns de suas principais figuras me permitiu indicar que existe diferenças importantes em suas trajetórias. Essas distintas origens acadêmicas, geracionais e nacionais, tiveram um impacto no modo como Dussel, Quijano e Mignolo participam do movimento decolonial.

O ensaio se concentrou, de fato, na versão de Mignolo sobre o pensamento decolonial. Por sua trajetória acadêmica, desenvolvida segundo uma grande influência da chamada "french theory" (Cusset, 2013), Mignolo parece como aquele que recebeu e absorveu de forma mais intensa os ventos das tendências céticas e críticas que Richard Rorty chamou de "ironistas". Segundo uma visão não-fundacionalista do conhecimento, 
Mignolo erigiu um edifício teórico que opera uma desconstrução do chamado pensamento moderno, além de apontar par anovas práticas teóricas e possibilidades existenciais. Através de sua "gramática" surge um univeso de relações, de estruturas transhistóricas e microfísicas de poder, mas também formas paradigmáticas de resistência a Colonialidade.

A estratégia de buscar contextualizar esse pensamento serviu justamente para indicar que a teoria de Mignolo nasce dentro do universo acadêmico, sendo marcada pela experiência do autor como sujeito diaspórico, procurando se firma de alguma maneira em um mercado acadêmico globalizado. Além do mais, sua influência marcadamente ironista parece colocar dilemas de difícil resolução para o autor argentino: como desconstruir macronarativas em erguer uma marcronarrativa autolegitimadora e que solapa a possibilidade de diálogo com os damnés ${ }^{28}$, elementos centrais para o que ele chama de "desobediência epistêmica"?

A tarefa posta é superar a tendência ao solipicismo intelectual e a projeção de metautopias que uma hiperteorização pode conduzir. Além do mais, não serve de nada uma postura muito berigerante em relação as matrizes disciplinares, algo que impede a recuperação de experiência uteis (no sentido decolonial) que existem nas mais diversas disciplinas como a sociologia, a filosofia e antropologia. Algo que pode contribuir para revalorização da dimensão pragmática da vida daqueles que enfrentam a colonialidade em seus cotidianos.

\section{Referências}

ÁLVAREZ SOLÍS, Á. O. (2010). La persistencia de los márgenes. Reflexiones epistemológicas en torno a la obra de Walter Mignolo. Araucaria, 12(23).

BALLESTRIN, Luciana. (2013). América Latina e o giro decolonial. Revista brasileira de ciência política, (11), 89-117.

\footnotetext{
${ }^{28}$ Se apropriando de uma categoria de Fanon (2001), Mignolo diz que "o damné não são apenas os pobres (na descrição marxista ou cristã), mas os 'menos humanos' que merecem, do ponto de vista de uma conceituação política e econômica do poder, ser pobres" (Mignolo, 2005, p. 383)
} 
BOURDIEU, Pierre. (2004). Usos sociais da ciência: por uma sociologia clínica do campo científico. Unesp.

BROWITT, Jeff. (2014). La teoría decolonial: buscando la identidad en el mercado académico. Cuadernos de literatura, 18(36), 25-46.

CASTRO-GÓMEZ, S. (2005). La hybris del punto cero: ciencia, raza e ilustración en la Nueva Granada (1750-1816). Edtitorial Pontificia Universidad Javeriana.

CASTRO-GÓMEZ, Santiago \& MENDIETA, Eduardo. (1998). La translocalización discursiva de Latinoamérica en tiempos de la globalización. Teorías sin disciplina.

Latinoamericanismo, poscolonialidad y globalización en debate, SMAP, México DF.

COSTA, SERGIO. (2006). Desprovincializando a sociologia: a contribuição póscolonial. Revista brasileira de ciências sociais, 21(60), 117-134.

CUSSET, François. (2013). French Theory: Foucault, Derrida, Deleuze et Cie et les mutations de la vie intellectuelle aux Etats-Unis. La Découverte.

DE MOJICA, Sarah. (1999). Con Walter Mignolo en el Instituto Pensar. Cuadernos de Literatura, 5(9), 106-113.

DEWEY, John. (1998). The essential Dewey: Pragmatism, education, democracy (Vol. 1). Indiana University Press.

DÍAZ, Mónica. (2014). El" nuevo paradigma" de los estudios coloniales latinoamericanos: Un cuarto de siglo después. Revista de Estudios Hispánicos, 48(3), 519-547.

DUSSEL, Enrique D. (2012). Ética da libertação: na idade da globalização e da exclusão. Vozes.

DUSSEL, Enrique D. (2000). Europa, modernidad y eurocentrismo. In: In: LANDER, Edgardo (comp.). La colonialidad del saber: eurocentrismo y ciencias sociales. Perspectivas latinoamericanas. Buenos Aires: CLACSO, 2000. p. 41-55.

DUSSEL, Enrique D. (1977). Filosofia da libertação. 2. ed. São Paulo: Loyola.

DUSSEL, Enrique D. (2016). Transmodernidade e interculturalidade: interpretação a partir da filosofia da libertação. Sociedade e Estado, 31(1), 51-73.

DUSSEL, E. D., \& FORNAZZARI, A. (2002). World-system and" trans"-modernity. Nepantla: views from South, 3(2), 221-244.

ESCOBAR, Arturo. (2003). Mundos y conocimientos de otro modo. El programa de investigación de modernidad/colonialidad latinoamericano. Tabula rasa, (1).

FANON, Frantz (2001). Los condenados de la tierra. Mexico: FCE.

FANON, Frantz (2008). Pele negras mascaras brancas. Salvador: EDUFBA.. 
FOUCAULT, Michel (2015). A arqueologia do saber. Rio de Janeiro: Forense Universitária.

FOUCAULT, Michel (2014). A ordem do discurso: aula inaugural no Collège de France. São Paulo: Edições Loyola.

FOUCAULT, Michel (2007). As palavras e as coisas: uma arqueologia das ciências humanas. São Paulo: Martins Fontes.

FRANZÉ, Javier. (2013). Fisonomía de la metafísica decolonial: lo damné, una identidad sin narración. Tabula Rasa, (18).

FUKUYAMA, Francis (1992). O Fim da História e o Último Homem. Rio de Janeiro, Editora Rocco.

GILMORE, Samuel. (1988). Schools of activity and innovation. Sociological Quarterly, 29(2), 203-219.

GROSFOGUEL, Ramon. (2012). The dilemmas of ethnic studies in the United States:

Between liberal multiculturalism, identity politics, disciplinary colonization, and decolonial epistemologies. Human Architecture: Journal of the Sociology of Self-

Knowledge, 10(1), 9.

GROSFOGUEL, Ramón; CASTRO-GÓMEZ, Santiago (Ed.). (2007) El giro decolonial. Reflexiones para una diversidad epistémica más allá del capitalismo global. Bogotá: Siglo del Hombre Editores.

GROUP. (1993). Latin American Subaltern Studies. Founding statement. Boundary 2, p. 110- 121.

HOYOS, Héctor. (2016). Hemispheric Studies Tomorrow. American Literary History, vol. 28 , no. 3, pp. 605-612.

JAMES, William. (1921). Pragmatism: A new name for some old philosophy, old ways of thinking: Popular lectures on philosophy. USA: Longmans, Green.

KUHN, Thomas S. (1998). A estrutura das revoluções científicas. São Paulo: Perspectiva, 2006.Latinoamericanismo, poscolonialidad y globalización en debate. México DF: Miguel Ángel Porrúa-University of San Francisco.

LYOTARD, Jean-François. (2009). A condição pós-moderna. Rio de Janeiro: José Olympio.

MALDONADO-TORRES, Nelson. (2007). Walter Mignolo: una vida dedicada al proyecto decolonial. Nómadas (Col), (26).

MANNHEIM, Karl. (2013). Sociologia da cultura. São Paulo: Perspectiva.

MARIÁTEGUI, José Carlos. (1975). Sete ensaios de interpretação da realidade peruana. São Paulo: Alfa-Omega. 
MARTINS, P. H. (2017). Norte e Sul como Referências para uma Ciência Social global: Transdisciplinar, Antiutilitarista e Pós-Colonial. Revista TOMO.

MIGNOLO, Walter D. (2009b). “Desobediencia Epistémica (II). Pensamiento Independiente y Libertad Decolonial”. Otros logos: Revista de Estudios Críticos. Centro de Estudios y Actualización en Pensamiento Político, Decolonialidad e Interculturalidad. Universidad Nacional del Comahue, v. 1, p. 8-42.

MIGNOLO, Walter D. (1993). Colonial and postcolonial discourse: cultural critique or academic colonialism? Latin American Research Review, v. 28, n. 3, p. 120-134.

MIGNOLO, Walter D. (2010). Desobediencia epistémica. Retórica de la modernidad, lógica de la colonialidad y gramática de la descolonialidad. Buenos Aires: Ediciones del Signo.

MIGNOLO, Walter D. (2003). Histórias locais/ Projetos globais: colonialidade, saberes subalternos e pensamento limiar. Belo Horizonte: Editora UFMG.

MIGNOLO, Walter D. (2001). La Contribucíon de Xavier Albó y Silvia Rivera Cusicanqui a la reestrutcturación de las ciências sociales desde los Andes. Rev. Venez. de Econ. Y Ciencias Sociales, v. 7, n. 3, p. 175-195.

MIGNOLO, Walter D. (2009a). La fin de l'université telle que nous la connaissons. Cahiers des Amériques latines, n. 62, p. 97-109.

MIGNOLO, Walter D. (2007). La Idea de América Latina. Barcelona: Editorial Gedisa.

MIGNOLO, Walter D. (1995). The Darker Side of Renaissance: literacy, territoriality and colonization. United States of America: The University of Michigan Press.

MIGNOLO, Walter D. (2011). The darker side of western modernity: global futures, decolonial options. Durhan \& London: Duke University Press.

MIGNOLO, Walter D.; ESCOBAR, Arturo (Ed.). (2013). Globalization and the decolonial option. Routledge.

O’GORMAN, Edmundo. (1995). La invencion de América. Mexico: FCE.

PORCILE, Gabriel. (2010). Heterogeneidade estrutural: conceito e evidências na América Latina. Revista Economia \& Tecnologia, v. 6, n. 2.

QUIJANO, Anibal. (2014). Cuestiones y horizontes. De la dependecia historic-estrutural a la colonialidade/decolonialidad del poder. Buenos Aires: CLACSO.

QUIJANO, Anibal. (2005). Dom Quixote e os moinhos de vento na América Latina. Estudos Avançados, v. 19, n. 55, p. 9-31.

RAMA, ÁNGEL. (2015). A cidade das letras. São Paulo: Boitempo. 
RICOUER, P. (1973). Freud: Una interpretaçión de la cultura. Tradución Armando Suárez. Madri: Siglo Veintiuno.

RORTY, Richard. (1989). Contingency, Irony and Solidarity. UK: Cambridge University Press.

SANTOS, Boaventura de Sousa. (2010). A gramática do tempo: para uma nova cultura política. São Paulo: Cortez.

SANTOS, Boaventura de Sousa. (2011) Para um novo senso comum: a ciência, o direito e a política na transição paradigmática. Cortez Editora.

WALLERSTEIN, Imamanuel. (2006). Impensar a Ciência Social. Aparecida, SP: Idéias \& Letras.

WALLERSTEIN, Imamanuel. (2007). O universalismo Europeu: a retórica do poder. São Paulo: Boitempo.

WALLERSTEIN, Imamanuel. (1996). Para abrir as ciências sociais. São Paulo: Cortez, 1996.

WALLERSTEIN, Imamanuel. (2004) World-Systems Analysis: an introduction. Duke University Press.

WALSH, Catherine \& CASTRO-GÓMEZ, Santiago. (2002). Indisciplinar las ciencias sociales: Geopolíticas del conocimiento y colonialidad del poder. Perspectivas desde lo andino. Editorial Abya Yala.

WASSERMAN, Cláudia \& DEVÉS, Eduardo. (2010). Pensamentos latino-americano: além das fronteiras nacionais. UFRGS Editora. 